\title{
APPLICATIONS OF THE LIGHT LASER WITH SPATIAL INCOHERENCE AND BIONIC OPTIMIZATION TO THE OPTICAL WIRELESS COMMUNICATIONS
}

\author{
APLICACIONES DEL DESCOHERENCIAMIENTO \\ ESPACIAL DEL \\ LÁSER Y DE LA OPTIMIZACIÓN BIÓNICA A LAS \\ COMUNICACIONES \\ ÓPTICAS INALÁMBRICAS
}

\section{THE LIGHT LASER WITH SPATIAL INCOHERENCE AND BIONIC OPTIMIZATION IN OPTICAL WIRELESS COMMUNICATIONS}

Samuel Ángel Jaramillo Flórez and Yuli Fernanda Achipiz ${ }^{1}$,

$\begin{aligned} & { }^{1 .} \text { Línea de Investigación en Gestión y Aplicaciones en Telecomunicaciones- } \\ & \text { LIGATEL, Ingeniería Electrónica, Universidad del Quindío, Armenia, Quin } \\ & \text { dío, Colombia }\end{aligned}$
$\begin{array}{r}\text { Recibido: } 20 \text { de febrero de } 2014 \\ \text { Aceptado: } 25 \text { de marzo de } 2014\end{array}$
Correspondencia del autor: Línea de Investigación en Gestión y Aplicaciones en Telecomunicaciones-LIGATEL,
Ingeniería Electrónica, Universidad del Quindío, Armenia, Quindío, Colombia
E-mail: samuelangel@uniquindio.edu.co

\begin{abstract}
The bioelectronics takes of the biology the optimized elements for to do a copy and to build technological mechanisms with functions based in that of body lives components. Telecommunications and biology present an analogy between the optical receivers and insects eyes, which forms are adequate to receipt signal since a transmitter, and these are been leaded to perfection by the nature during millions of years in the environment adaptation. The sizes and the forms depend of the direction of the waves and of the radiation pattern of these biotransmitters and bioreceivers (omatidies of insects eyes), which is similar as the optical communications emitters and photodetectors. The growth of the telecommunication services makes necessary the optimization of the bandwidth of the transmission channels. Although the optic transmission is considered like the ideal as for the attenuation and distortion characteristics that make that it possesses the better relation bandwidth - longitude, the demand of more transmission capacity forces to take advantage of them efficiently. High costs generated when deploying Optic Fiber Networks at the transport level, together with other factors that avoid PONs arriving to the home and/or office, have impulsed the design and implementation of partially optical networks (FITL), including an alternative that uses infrared light. This work explores the basis of these news access networks, and it is presented an optical communication transmission/reception system with optic channel of free space where has been modulated the transmitter laser through a set of spherical lens and optical fibers that expand the beam of light to different points of an indoor enclosure producing multiple punctual images located in positions that permit to determine and to optimize the bandwidth of the system. The computational simulation results are showed and are compared with those experimentally measured, indicating that this is an original method for to design emitters and receivers of high performance for optical communications.
\end{abstract}

Keywords: Bioelectronics, photodetectors. photoemitters, omatidio, broadband, Free Space Optics (FSO), optoelectronics, spatial coherence, wireless optic communications, spatial modulation, laser. 


\section{RESUMEN}

La Bioelectrónica toma de la Biologia los elementos optimizados para copiarlos y construir mecanismos tecnológicos con funciones basadas en los componentes de los seres vivos. Las Telecomunicaciones y la Biología presentan una analogía entre receptores para comunicaciones ópticas y los ojos de los insectos, cuyas formas son apropiados para recibir señales desde un transmisor, y estas se han ido perfeccionado por la naturaleza durante millones de años en su adaptación al medio ambiente. El tamaño y la forma dependen de la dirección de las ondas y del patrón de radiación de estas biotransmisores y bioreceptores (omatidios en los ojos de los insectos), que son semejantes a las emisores y receptores utilizadas en comunicaciones ópticas. Aunque se considera el medio óptico de transmisión como el ideal en cuanto a las características de atenuación y distorsión, que hacen que posea la mejor relación ancho de banda - longitud de enlace, la exigencia de mayor capacidad de transmisión obliga a aprovecharlos eficientemente. Los altos costos generados cuando se instalan redes de fibra óptica al nivel de transporte, junto con otros factores que evitan que las redes ópticas pasivas - PONs - lleguen a la casa y/o a la oficina, han impulsado el diseño y la implementación de redes parcialmente ópticas (FITL), incluso una alternativa que usa luz infrarroja.

Este trabajo explora las bases de estas nuevas redes de acceso mediante un sistema de comunicación óptica de espacio libre, en donde se ha utilizado un arreglo de fotoemisores/fotodetectores distribuidos espacialmente acondicionado mediante un juego de lentes esféricas y de fibras ópticas que concentran el haz de luz desde diferentes puntos de un recinto interior con múltiples imágenes puntuales localizadas en posiciones que determinan y optimizan la discriminación y el ancho de banda del sistema. Se discuten, además, los resultados experimentales y se comparan con los obtenidos mediante simulación computacional, indicando que este es un método original para diseñar emisores y receptores en sistemas de comunicaciones ópticas de elevado desempeño.

Palabras clave: Bioelectrónica, fotoemisores y fotoreceptores ópticos, omatidio, banda ancha, coherencia espacial, ccomunicaciones ópticas inalámbricas, Free Space Optics (FSO), modulación espacial, láser, óptica de espacio libre, optoelectrónica. 


\section{INTRODUCTION}

The competitive companies of telecommunications carries of new services must fight to install alternatives broadband access networks to the subscriber's telephonic networks already installed in the majority of the homes and offices. The costs of installation and operation associated with the implementation of the links and the equipments of transmission and commutation in the optical access networks might justify when the subscriber's density was promising sufficient money to recover the investments and to obtain the awaited earnings. In case the economic estimations or the political ones of the carry company of the optical network do not allow the arrival of the fiber up to the facilities of the final user, there is necessary the installation of access networks named "secondary" that achieve a relation Quality of Service vs. Financial Costs high enough in order that such a competitive company achieves the programmed profitability and offers the awaited service. This, as for service of accesses of broadband (to Internet, for example) for residential users and companies with not very high information flows[1]. On the other hand, there are local area networks (LANs) that need of links of low budget and facility in his installation. Also there exist needs still not satisfied of an ideal way, as for access networks for users with low mobility (or mobility of low speed), which need of low costs of connection and multiply applicable. A wireless technology, of low consumption, cost, high accounting, capacity adapted to the needs of such users' classes and high facility of installation, would turn into a solution of advanced into environments where the density and the growth of final users is very irregular, so much from the point of view of the number of subscribers like for the geographical areas and the random locations in which these are.

A set of equipments network and information devices based on the transmission for infrared light, is being offered by several manufacturers, including peripheral of computer, hand devices and all kinds of devices of information that obtain good applicable capacity acceding to high speeds to Internet, constituting a access network of optical complementary technologies: fiber and free space optical transmission(FSO) [2].

The bioelectronics takes of the biology the optimized elements for doing a copy and building technological mechanisms with functions based on living bo- dies' components. Telecommunications and biology present an analogy between the optical receivers and the insect's eyes, whose forms are adequate to receive signals from a transmitter, and which have been improved by the nature during millions of years in the environment adaptation. The sizes and the forms depend on the direction of the waves and on the radiation pattern of these biotransmitters and bioreceivers (omatidios of insects eyes), which are similar to the optical communications emitters and photodetectors.

The growth of the telecommunication services makes necessary the optimization of the bandwidth of the transmission channels. Although the optic transmission is considered like the ideal as for the attenuation and distortion characteristics that make that it possesses the better relation bandwidth - longitude, the demand of more transmission capacity forces to take advantage of them efficiently. High costs generated when deploying Optic Fiber Networks at the transport level, together with other factors that avoid PONs arriving to the home and/or office, have impulsed the design and implementation of partially optical networks (FITL), including an alternative that uses infrared light.

In this paper is presented an optical communication system with optic channel of free space where is modulated the transmitter laser through a set of spherical lens and optical fibers that expand the beam of light indoor producing multiple punctual images that permit to optimize the bandwidth of the system.

\section{INFRARED TRANSMISSION SYSTEMS}

Information transmission systems based on sending and receiving optical signals, wired or wireless, work over infrared (IR) electromagnetic spectrum range. Transmission systems based on optic fibers, propagate infrared light along low attenuation and high linearity areas of such transmission media, which are in the wavelength regions of $1310 \mathrm{~nm}, 1550 \mathrm{~nm}$ and 850 $\mathrm{nm}$. Different to that optical systems by fiber, optical transmission systems through the free space does not use a guided medium to propagate the signal. In such a systems the designers does not care about uses infrared energy in the wavelengths aforementioned, but their design aims over the physical level concentrates on getting the more propagated distance without fading infrared light power below that observable by the detection system [3]. An infrared transmission system 
is composed by a transmission device, a reception device and a propagation medium with characteristics for optimal optic transmission.

The transition media is the vacuum (in this case the air) and presents a sum of an electromagnetic propagation resistance factors on infrared wavelengths. Such a sum is the result of free space losses (that can be calculated by using the Friis expression), lobe fading, intensity losses caused by high temperatures (by the generation of vapors that makes refractions), atmospheric depressions (rain and fog) and, as a primordial factor, the need for a line of sight between transmitter and receiver to establish the link.

The emitter system for infrared transmission (see Figure 1) is composed by a modulation block and a radiation source on that spectrum region. Such a radiation source is generally constituted by an infrared emission diode (IRD) or infrared laser diode (ILD) manufactured on Gallium Arsenium and whose crystal case can reach highly collimated radiations, or well lobe widths of up to $30^{\circ}$ (see Figure 2), depending on if it uses, or not, physical optic for its output structure (mirrors and convergent lens). Detection systems, or receivers, are composed by photodiodes or phototransistors, made of Silica or Germanium, the Germanium being the better one absorber of intensity over a wide infrared spectrum range (see Figure 3).

\section{NETWORK PROTOCOLS FOR INFRARED ACCESS}

Having high velocity access networks is an idea that implies thinking about two levels non hierarchical SDH/SONET networks providing the multi-technology access networks with high payload bandwidths throughout all of its add/drop multiplexers (ADM access nodes).

The protocol paradigm of medium access over passive broadcast networks. or even in active multiplexed networks, is the Asynchronous Transfer Mode (ATM). It can calculate distances in terms of clock pulses, in order to obtain a transmission convergence and make the broadcasting, sending and receiving of ATM cells.

These cells are inserted on the SDH/SONET cells payload.

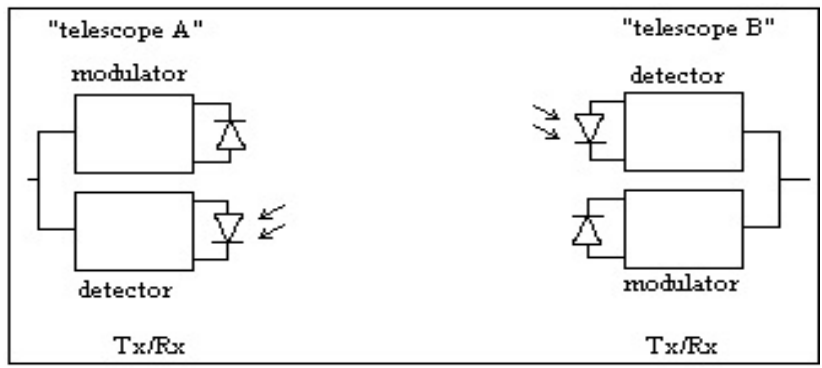

Figure 1. Simplified squeme of a bidirectional infrared transmission system.

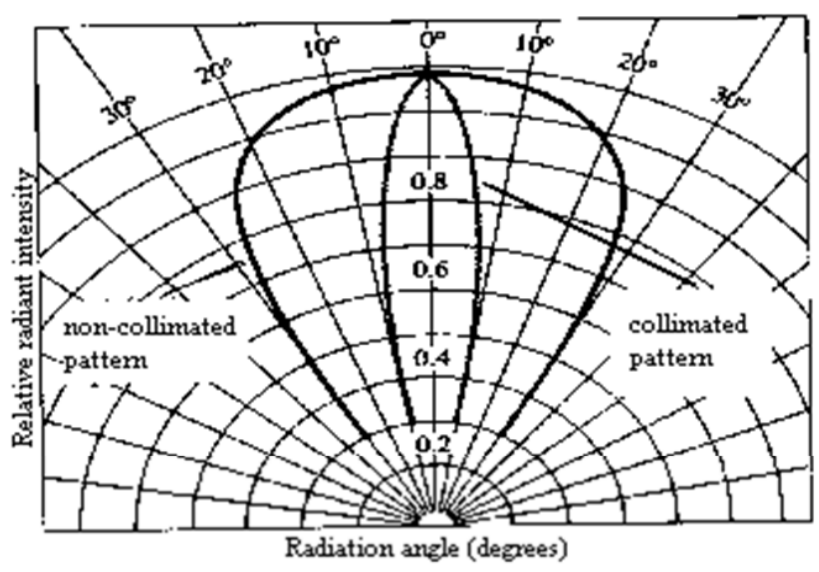

Figure 2. Typical radiation patterns, collimated and not collimated, for an infrared source diode.

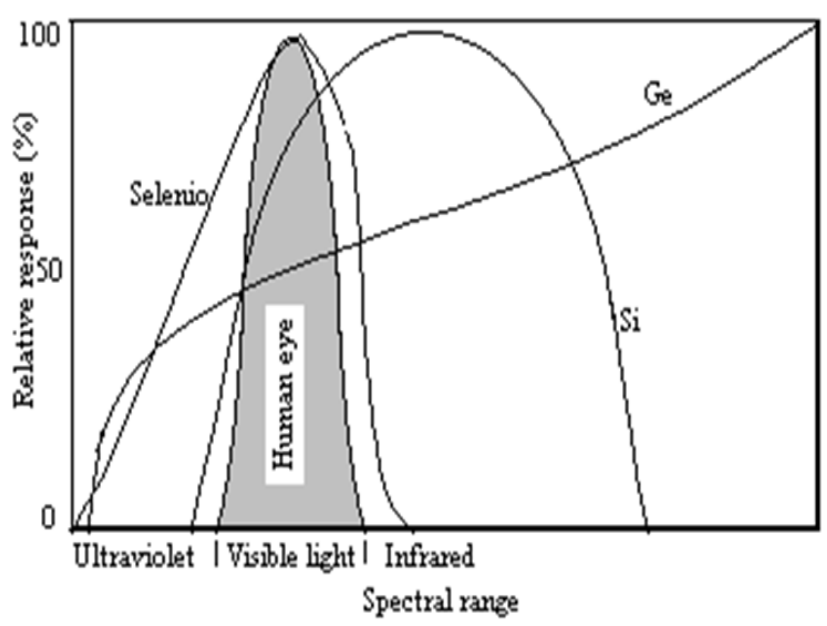

Figure 3. Spectral sensibility of Ge, Si and Selenium regarding human vision.

So, with the establishment of ATM virtual circuits, and at the same time using synchronous digital hierarchy virtual containers, the subscriber's access into the transport network can be done by interconnecting them with data networks: Internet, or other private and public networks [4]. 
Passive Optical Networks (PON) have the architecture that uses ATM as its data link and medium access control protocol, although actually exist two well known and proven protocols, Ethernet and Gigabit Ethernet, are intended for bringing efficient protocols and interfaces set to communicate subscribers and ISPs [5].

All Information Appliances that are being developed in the new wave of Home Networking uses Internet access through gateways connected to access networks. These environments will be very important business targets, taking into account the infrared transmission as an efficient alternative, costs-effective and easily deployable along Internet broadband access networks. There are two main wireless technologies to use in home networking products: Infrared (IR) y Radiofrequency (RF). Until now, most of the developers and vendors has seen infrared networks like a corporate medium-low scale LANs technology or as a technology that makes possible interconnecting several appliances (information applications or devices) into a house, room, SOHO (Small Office/Home Office) or whatever business with medium data flow level[6]. However, the scope is that in the near future besides having LAN infrared networks inside a house, it also can obtain broadband access through networks based on IR topologies like those proposed on the next section. In addition to the use Ethernet and ATM, and even directly SDH/SONET frames, as the interfaces and protocols for data link and medium access control, in the world it exists de facto protocols proposed by Infrared Data Association (IrDA), among other proprietary ones, see Figure 4, and adopted by all information appliances and access networks developers, designers and manufacturers using this technology, including application software made by Microsoft and Linux [7].

When an access network is implemented using equipment based on the protocols set of IrDA (see Figure 4), ATM and SDH/SONET protocols, and hence TCP/IP protocols (the most used over ATM), would perform its functions over the Network Layer (having into account the TCP/IP network model). On the other hand, using only the standardized IrDA Physical Interfaces and Protocols, ATM or Ethernet standards adopts the roles of data link, transmission convergence (in the ATM case) and network layer (TCP/IP, ATM and/or Ethernet) (see Figure 5).

\section{FSO ACCESS NETWORKS TOPOLOGIES}

Fiber Into The Loop (FITL) constitutes the paradigmatic revolution at the moment. The longer penetration the optical fiber have in the local loop side, the longer data and services capacities could be offered by the optical carrier (network operator) and the other competitive carrier companies (CLECs). Access networks containing some part (or parts) of it running over optic fiber links are classified in Fiber To The Home (FTTH), Fiber To The Building (FTTB), Fiber To The Curb (FTTC) or Fiber To The Cabinet or pedestal (FTTCa) (see Figure 6) [8]. On the classification above the most indicated environments where combining optic fiber with short range high performance transmission technologies are: FTTC and FTTCa.

\begin{tabular}{|c|c|c|c|c|}
\hline \multirow{2}{*}{$\begin{array}{l}\text { IrTRAN } \\
\text { LIM-IAS }\end{array}$} & Irober & \begin{tabular}{l|l|l} 
IrLAH & IrCO \\
\end{tabular} & \begin{tabular}{l|l|} 
IrMC \\
\end{tabular} & \multirow{2}{*}{$\begin{array}{l}\text { Aplication } \\
\text { Transport }\end{array}$} \\
\hline & \multicolumn{3}{|c|}{ Transport Protocol Tiny-TinTP } & \\
\hline \multicolumn{4}{|c|}{ Lirlk Management Ir-IrLMP } & MAC \\
\hline \multicolumn{4}{|c|}{ Lirl is ceess Protocol -IrLAP } & LIC \\
\hline $\begin{array}{l}\text { Serial } \\
\text { Asychor } \\
(9.6-115\end{array}$ & $\begin{array}{l}\text { mous } \\
2 \text { Kbps) }\end{array}$ & $\begin{array}{l}\text { Serial } \\
\text { Synchromous } \\
\text { (1.152 Mbps) }\end{array}$ & $\begin{array}{c}\text { Syme } \\
\text { 4PPM } \\
\text { (4 Mbps) }\end{array}$ & Plysical \\
\hline
\end{tabular}

Figure 4. IrDA Protocols Set

Infrared light links are more reliable and faster when the range (distance) that it must cover is smaller. Therefore, designing access networks for distributing bandwidth among certain areas, each of which covers some hundreds of meters in diameter, is a new opportunity that can be used by competitives and news companies to deploy access networks driving the optical fiber deployed up to the Curb or Cabinet (pedestal), that can be offered by high velocity transport networks carriers (see Figure 7).

\begin{tabular}{|c|c|c|c|}
\hline TCP & \multicolumn{2}{|c|}{ UDP } & Transport \\
\hline \multicolumn{3}{|c|}{ TCP/IP } & Network \\
\hline \multicolumn{3}{|c|}{ Transmision Convergence } & MAC \\
\hline \multicolumn{3}{|c|}{ ATM } & LLC \\
\hline $\begin{array}{l}\text { Serial } \\
\text { A synchronous } \\
(9.6-115.2 \mathrm{~Kb} \text { bps })\end{array}$ & $\begin{array}{l}\text { Serial } \\
\text { Synchronons } \\
\text { (1.152 Mbps) }\end{array}$ & $\begin{array}{l}\text { Syne } \\
\text { 4PPM } \\
\text { (4 Mbps) }\end{array}$ & Phyrsical \\
\hline
\end{tabular}

Figure 5. Application of IrDA protocols in an access networks environment, for example in order to get Internet access. 
A Passive Optical Network (PON) topology has an OLT (Optical Line Termination), an ODN (Optical Distribution Network) and, in order to make the interface with multitude of complementary access technologies, considered as "secondary" access networks (of course, including FSO), an ONU (Optical Network Unit). These are the PON components and elements, which represents the most designed and deployed access network configuration throughout the globe (see Figure 8) [8].

Choosing network element capacities is the key for introducing FSO, including ILEC's or CLEC's ONUs and carrier's ADMs that communicate with infrared user terminals on one side, and with those ONUs on the other side. It must be considered the protocol set used for Mux/Demux infrared access equipment, since PONs has standardized processing velocities working over ATM and, has actually developed, over the Ethernet and Gigabit Ethernet protocols. ONU has four main parts: Interface with ODN part, ATM cells assembling and multiplexing part, adaptation functions part and, with standardized Q3 interfaces, OAM control and management part.

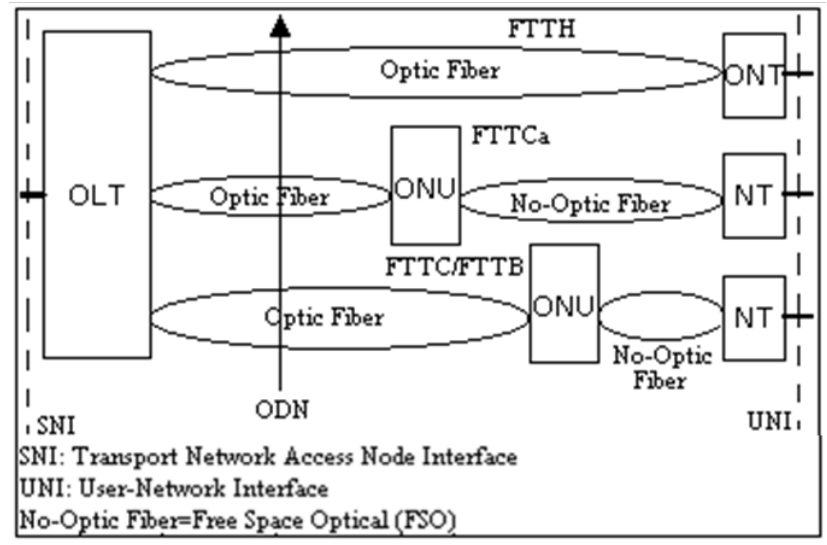

Figure 6. FITL Topologies enabling FSO.

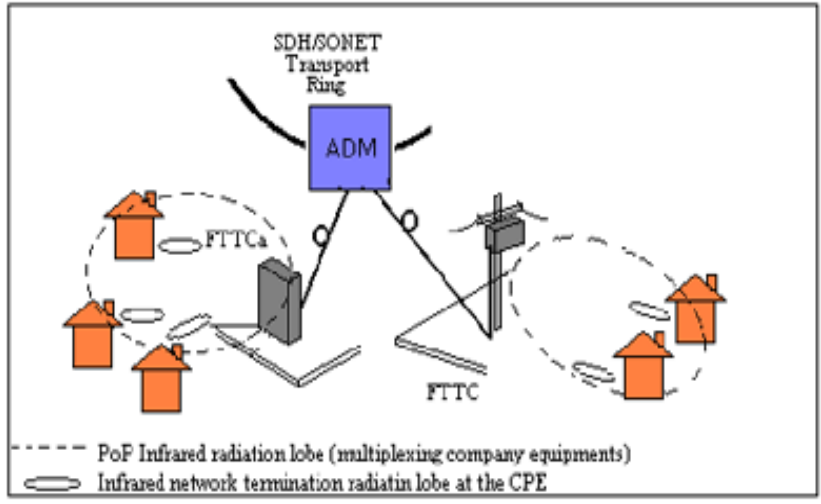

Figure 7. FTTC and FFTCa topology environments using Free Space Optical (FSO).
The links for infrared light are more reliable and rapid among minor it is the distance that they should cover, for which to design infrared access networks distributed in areas of a few hundreds of meters of diameter is an opportunity that carries competitive companies and new companies can use to install access networks taking advantage of the laying of optical fiber on Fiber To The Cabinet or pedestal (FTTCa), which there can offer the carries of networks of transport of high velocity [8].

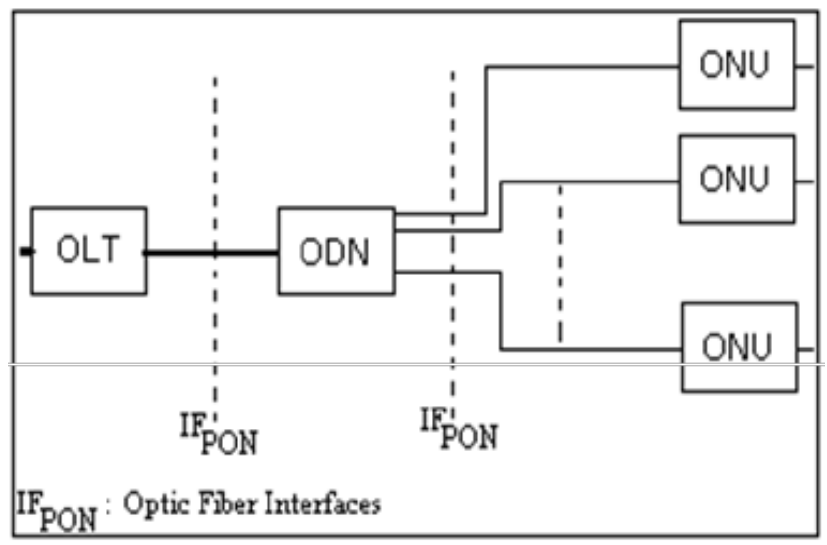

Figure 8. PON Components.

FSO: Free Space Optics/Optical consists of the utilization of the propagation of infrared light across the free space (the air) to transmit information (see Figure 9). The objectives with regard to the systems of transmission FSO consist of developing links point - to - point that work of the most reliable form that could be achieved and with the capacities in velocity of transmission and distance needed, in order to use in systems of networks of computers LAN, lines rented of high velocity for corporations and medium companies, systems of safety transmission to protect the transmission of sections of networks of optical fiber or other transmission systems and, finally, access networks to provide proper velocities of networks of optical fiber for residential users and of SOHOs.

The applications above mentioned are classified inside the problem of the "last mile of broadband "on the part of the companies manufacturers of systems

FSO and of access networks of Broadband Access Networks. The Figure 10 shows the typical topology with base in which they have designed and installed networks of access and, in general, networks of last mile. Using FSO in FSOAN (FSO Access Network) of broadband one has given till now in systems point to point. Due to the fact that already was mentioned 
it brings over of the classes of links FSO that are accepted to be included inside the classification of "last mile", the topology of the FSO network only changes into some few elements. In the Figure 11 appear the classified cases. FSO are two: nodes elements of commutation and nodes elements of the system of transmission. The network elements that form the set of an access network A topology point to multipoint can be designed and installed by a number $n$ of nodes and a number $n-1$ of links FSO. The nodes fulfill the functions of commutation, routing and multiplexing needed according to the protocols and the technologies of access network and transport network used. In the Figure 12 a network shows itself point to multipoint. In this one two classes of nodes can be defined: The node of access to a network of transport and the nodes of access to the FSOAN. There exist two classes of transmission and receipt system FSO. The first one and more used is the one that realizes a double conversion: optics - electric-optics O-E-O (see Figure 13).

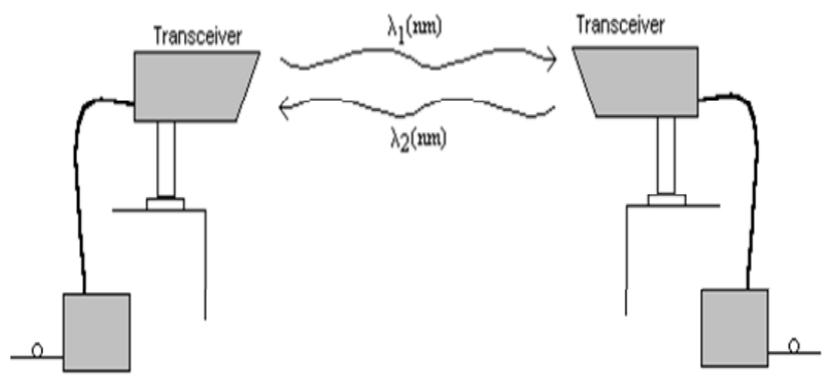

Figure 9. System of transmission simple FSO.

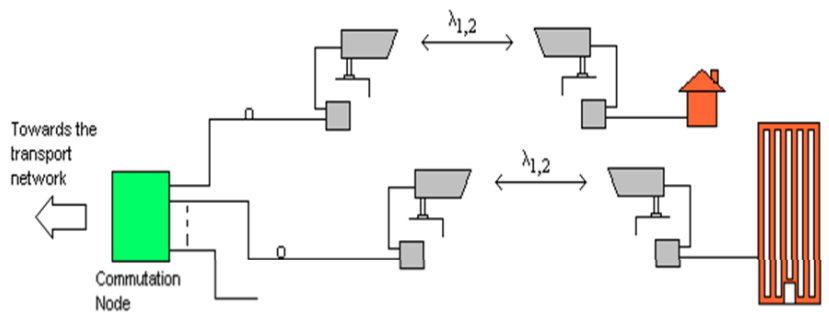

Figure 10. Basic topology of access network FSO.

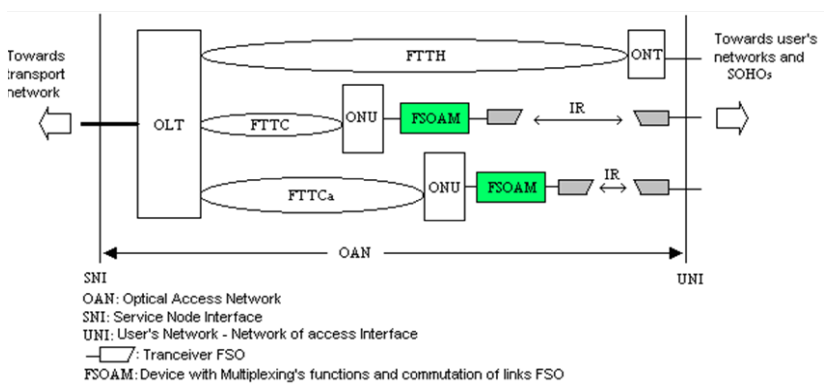

Figure 11. Cases classified as the concept of access network.
The second one does not realize really a conversion in the energy: optics - optics, though the latter might be thought as optics (fiber) - optics (free space) O-O. In the Figure 14 there appears a system FSO of the class that has qualified like O-O. The signal that is inserted in the transmitter propagates for an optical fiber, generally with a wavelength of $1550 \mathrm{~nm}$. The above mentioned signal is amplified in a subsystem amplifier doped by Erbium (EDFA: Erbium Doped Fiber Amplifier) and it is then emitted to the free space across a system of lenses that realize a function of concentration of the wave that comes of the optical amplifier and leave the wave goes out to the free space. In the receiver system the wave infrared passes for a system of convergent lenses, which insert it in an optical fiber.

\section{FSO NETWORK ARCHITECTURES}

At this point, the most important part to have into account is the interface between ONUs and the concentration and multiplexing equipment in the secondary FSO. The key thing is to understand an ONU function (see Figure 15).

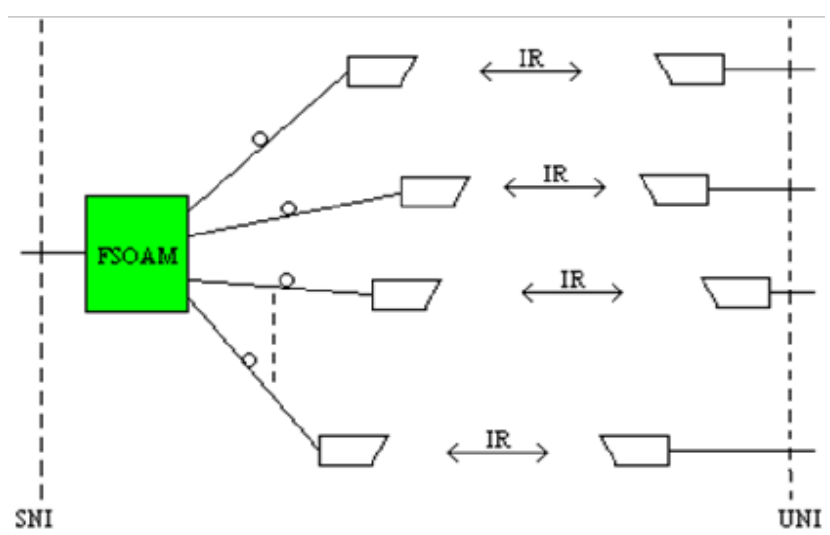

Figure 12. Pseudo-topology point to multipoint.

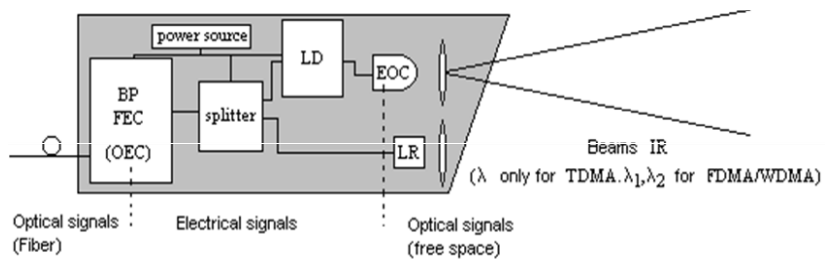

Figure 13. FSO with conversion O-E-O.

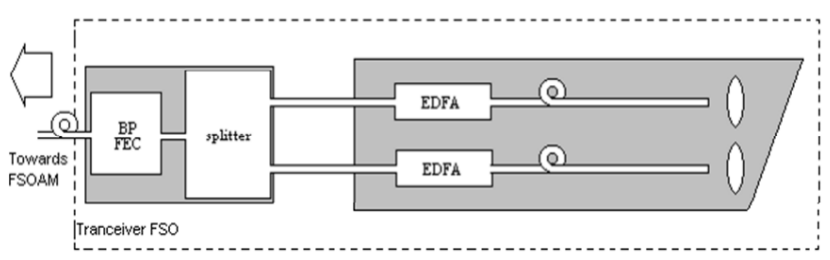

Figure 14. FSO without conversion of energy (O-O). 


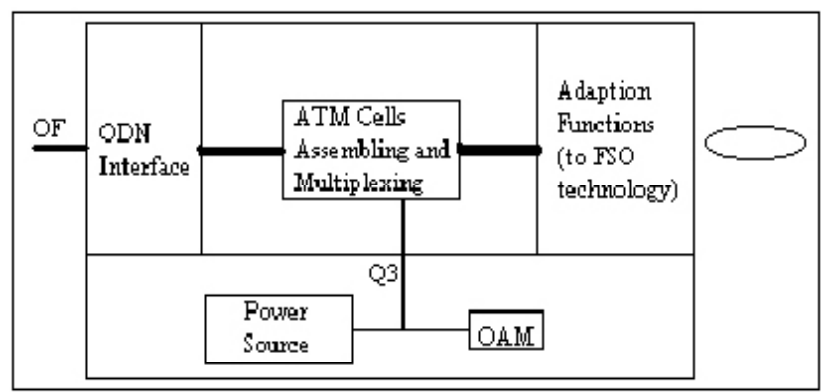

Figure 15. Internal simplified scheme of an ONU.

For the FSON/PON data interface and physical part, is necessary for ONU's respective adaptation functions designing send-receiving and infrared access Mux/ Demux for broadcasting multiple users and, in some special cases, for adapting data flows driven through point-to-point infrared links. The integration of ONUs, Mux/Demux and ATM (or Ethernet) assembling cells systems, is done in one functional package or modular equipment, in the same way that it was done with DSLAMs (Digital Subscriber Lines Multiplexer) and ATM switches. In the infrared scheme, such integrated equipments include all logical elements necessary to operate and interface with ATM/Ethernet PON systems, realizing subscribers multiplexing to IR links and doing the assemble and management of unit cells on the protocol used for data link and network access in general. An integrated system as the one described above, would exhibit an access network topology for both FTTC and FTTCa, having into account that in-pole installations as a particular case of FTTC is the most indicated choice for making a secure line of sight infrared broadband links.

\section{ACCESS NETWORKS MODEL DESIGN APPLIED TO FREE SPACE OPTICAL}

It is necessary to make a definition regarding the levels at which telecommunications networks can be studied, just like for determining on which of those levels to realize the reasoning. All of this with modern broadband access networks on the scope and especially in the case of Free Space Optical. Here it is offered a choice that consists on a four abstraction levels organization. The four levels that compose the telecommunications network design model have been proposed regarding to precedent models and looking for the most complete model possible, that save the designing work from most imprecision, interpretations and descriptions less complete used in the literature. Management, Functional, Architectural and Physical levels, are only the first step to reach such problem's solution; it is good as a point of reference in the multidimensional space of telecommunication networks design, as well. It will only be taken into account the functional level from the four levels mentioned above, hence in the example exhibited on the next section it will be supposed several aspects that prevent the need for designing at the management level and, much less, at the architectural and physical level, where the manufacturers does their work.

\section{Functional Level}

At this level engineers and scientists are thinking about information transmission capacities that the network must to match. Thinking about that as an organization of sub-systems and taking those, at the same time, as functions correlating input and output capacities. At this point it have to think about geographical extensions to be covered by the network, transmission magnitudes for the services required by subscribers, dividing the network into levels and sections (actually in two levels: Transport level and Access level) and its organization using blocks or parts (subsystems) that perform the access, switching and transport global functions. The Telecommunications Management Network (TMN) must be taken into account designing at this abstraction level, since it requires its own capacity, functional blocks and interfaces to intercommunicate with manageable network elements [9].

\section{Functional Design Level Applied to Secondary FSO Networks.}

In the section above were defined the activities that will be done on the next example. A secondary FSO network, offering broadband access to Internet requires basically of a PoP (Point of Presence), an infrared subscribers links multiplexer equipment and Infrared Network Terminations (INT) (Figure 16), which are directly connected to the consumer premises equipment. Using an infrared-through-the-window (IrTW) scheme, the link between PoP (composed by an ONU and an infrared multiplexer) and consumer premises equipment consists of an infrared electromagnetic energy beam flying across the home or office windows glasses. About the TMN, it will only be taken into account that PoP equipment, that includes carrier's ONUs and infrared subscriber's access multiplexing equipment owned by the CLEC (EtherLEC, ATMLEC or whatever broadband access company), it must have into its functions a system block whose interface is Q3, necessary for control and management (OAM) of the capacity resources agreed with the con- 
sumer by means of SLA (Service Level Agreement). In the analysis of geographical extension to be covered it is necessary to consider that reachable distances for infrared links show much variation with the different manufacturers, however there is a "virtual agreement" about those access links: For the scenario of "secondary" FSO access networks, those must be between several hundred meters and maximum 500 meters.

Finally, and before we are going to play with some little numbers, it must be taken into account that

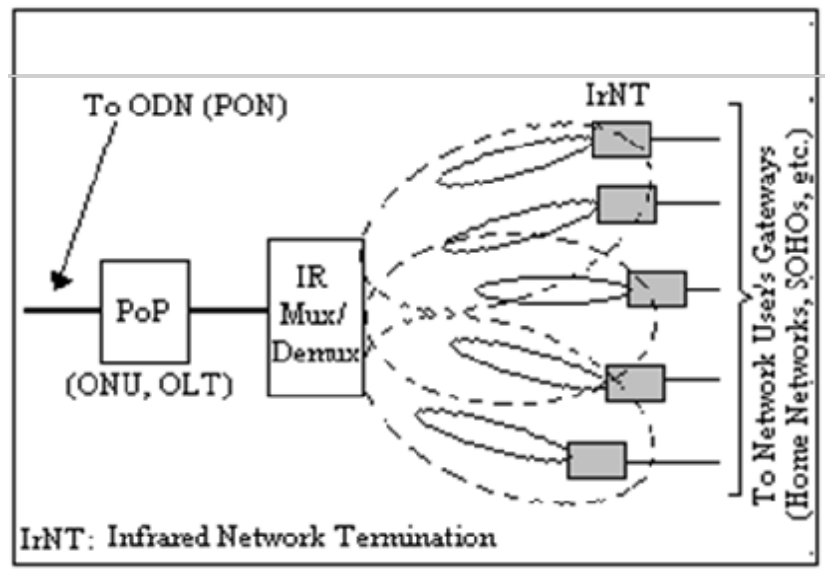

Figure 16. Simplified scheme of a "secondary" topology based on FSO.

capacities of PoP equipment owned by PON proprietary carrier companies (ILECs, EtherLECs or CLECs), can be used to estimate the users quantity that it can serve and the quality of service (QoS) provided (maximum transmission velocity for each user). BIONIC

The movement of the animals in the air and in the water decides for the evolutionary development of the biological systems, adapted to the solution of the problems of the aero and hydrodynamics and in a series of cases that are not for the present accessible to the artificial devices. The skin of the dolphin possesses special properties that allow diminishing any resistance to the movement of the animal. The flight of the wings jambs or that land of the birds is used as example to construct the flying devices for the man. The branch of the science dedicated to the technical employment of the mechanisms developed by the living nature is named Bionic. It was initiated by Leonardo da Vinci, who projected the wings for the flight of the man. He was the founder of the Biomechanics in its set on having studied for the first time the march, the career and the jump of the man. To the Biomechanics also does reference to the receipt of the mechanical oscillations and the orientation of the body for the organs of balance (organs otolites of the ear). The biomechanics researches are very essential for the technology and the medicine. The Biomechanics and the Bionic are branches of the Biophysics.

\section{EYES OF THE INSECTS}

The eyes exist in several plagues in which both the non-insects and the insects are included. The spiders like the black widow are plagues but they are not insects. The insects possess three principal parts in your body that are: (1) head, (2) thorax, (3) abdomen [10]. The spiders have two principal parts in your body: (1) abdomen, (2) cephalothoraxes. In the top part of the cephalothoraxes of a spider black widow arranged in two rows, one on other one, possesses eight simple eyes. (Some spiders have only six simple eyes). Some insects have both types of eyes, simple and compound, as the bees of honey, the yellow jackets and the flies. These simple eyes are usually placed in a triangular model in the front or in the top part of your head. In these examples, the simple eyes play the function of meter of light and beyond this, there exists the speculation that they serve them somehow to orientate the insect while this one flying. The majorities of the insects possesses only compound eyes and are totally different from the simple eyes. These compound eyes can be very small with relation to the size of the head of the insects as in case of the fleas. They can cover much of his your sides, face, or in the part of above of the head, as in case of the flies and cockroaches. A meticulous sight in the surface of a compound eye reveals that is divided inside a number of hexagonal facets, all facts to the measure as a surface of mosaic in tile. Every hexagonal unit has your proper lens and your proper retina and shows an image independent from any another unit in the mosaic. All the hundreds of facets cross the face of the compound eyes producing your proper pictures. Besides this, an insect can observe an object from different perspectives, all at the same time. These types of eyes do not produce to a clear vision as can focus the lenses to be able to do it in the eyes of the human being. There exist "pre-molten and pre-measured" lenses. Nevertheless they are of great help in the determination of the movement (probably hundred or more units choose this movement simultaneously) and they help to detect a change in the intensity of the light. To reduce the field of vision of every omatidium is sufficient to diminish the diameter $d$ of his optical small stick, making it commensurable with the dimensions of the image 
of diffraction, according to one show in the Figure 20. The decrease of the diameter of the optical small stick up to a minor dimension that the diameter of the image of diffraction does not reduce the visual width of the omatidium but it reduces the photosensibility, since the number of photoreceivers in the small stick will diminish.

The ideal diameter of the optical small stick of the omatidio is $d=f \Delta \alpha$, where $\mathrm{f}$ is the focal distance of the lens of the omatidium. In this case there is obtained the minimal possible narrowness of the field of vision of the omatidio equal to $\Delta \alpha$, being maximum your sensibility to the light. It is necessary to construct the eye in such a way that when the punctual light source leaves the field of vision of an omatidium, this source, immediately, should appear in the field of vision of an individual omatidium[10].

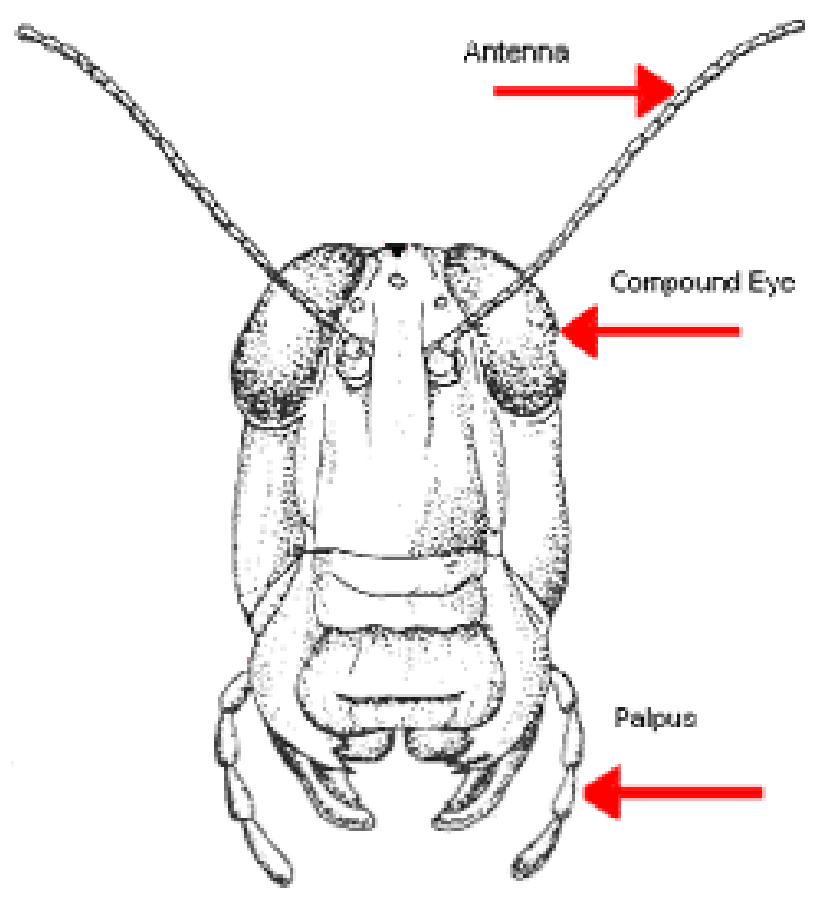

Figure 17. Distribution of the eyes in an insect showing his location to optimize the angle of arrival of the light.

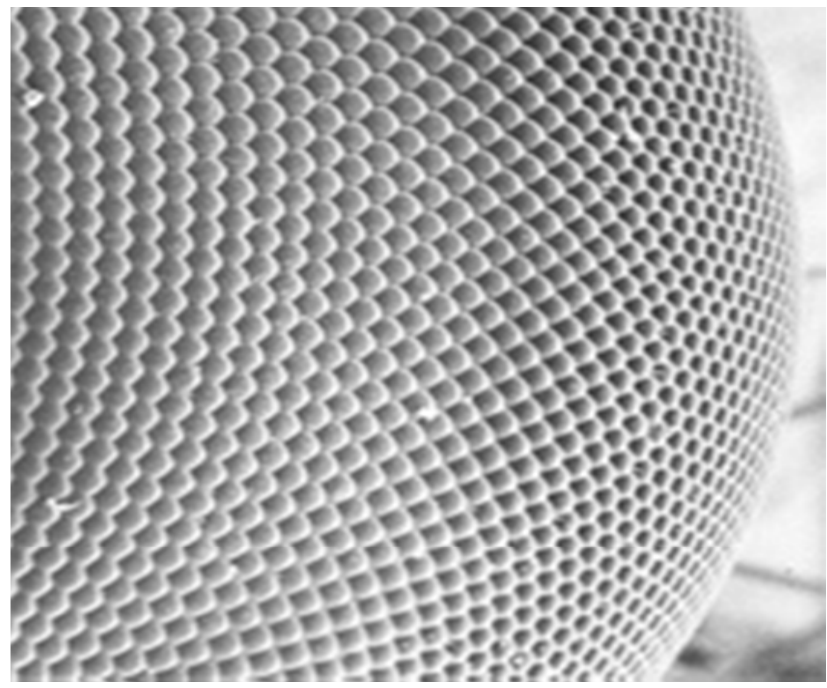

Figure 18. Eye in a fly showing his location to optimize the angle of arrival of the light.
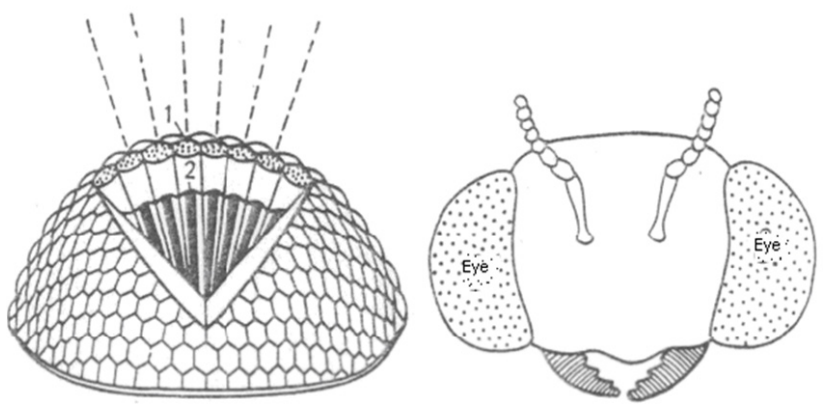

Figure 19. (a) Schematic cut of the compound eye of the insect: 1, Lens of the omatidium; 2, Visual small stick of an unitary omatidium. The lines of outlines indicate the directions of the optical axes of the neighboring omatidies, (b) Disposition of the eyes in the head of the insect.

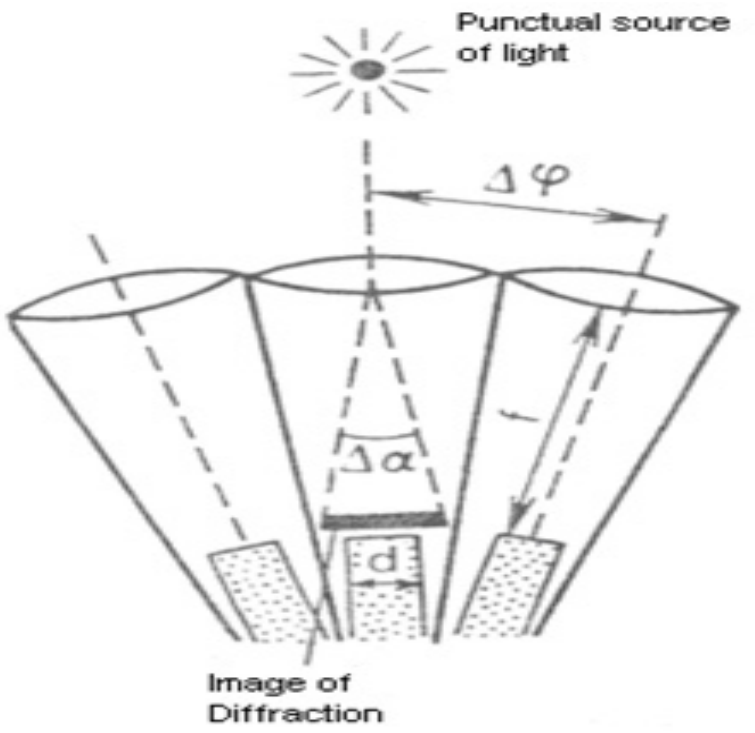

Figure 20. Dimensions of the omatidio of the compound eye. 


\section{RESULTS}

To take advantage totally of the reflections of the infrared beams for the wireless communications in closed enclosures, since every place at which one is employed changes his symmetry, is necessary bear in mind aspects like the walls, roofs, or any other obstacle that one presents this way to optimize the communications. There has been designed a software that allows to calculate the variations of the environment in different configurations where an equipment of communication is installed. Using a program of simulation of the channel of optical communications not guided for infrared and with an experimental accomplishment in the laboratory, data have been took, doing incoherence spatially the beam of the laser and taking measurements of distance from the laser towards the obstacle where the beam is reflected [11],[12]. A photoemmitters and photodetectors system were designed and constructed using hemispheres of $6 \mathrm{~cm}$ of radio with spherical lenses of $2 \mathrm{~cm}$ of radio and optical fibers of plastic of $5 \mathrm{~mm}$ of diameter. One thought that this one is the ideal structure for transmission and receipt when it is compared with an array planar with the same number of spherical lenses (50), see Figure 26.

The radius of the semisphere was calculated by the expression $R e=f D / d$, where $\mathrm{D}$ is the diameter of the spherical lens $(2.0 \mathrm{~cm}), \mathrm{d}$ the diameter of the optical fiber $(0.5 \mathrm{~cm})$ and $\mathrm{f}$ is the focal distance of the spherical lens $(1.5 \mathrm{~cm})$, calculated with the expression $f$ $=n R / 2(n-1)$, being $n=1.5$ the index of refraction of the glass and $R$ the radio of the spherical lens $R=$ $1 \mathrm{~cm}$ (see Figure 23).

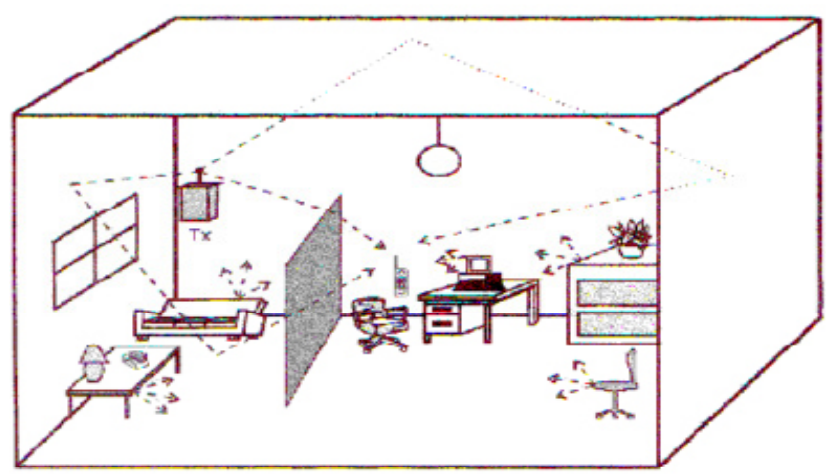

Fig. 22. Application of the spatial incoherencing of the laser to the optical wireless communications indoor. Being located appropriatly the array of points inside the room will be able to optimize the velocity of transmission[13], [14].

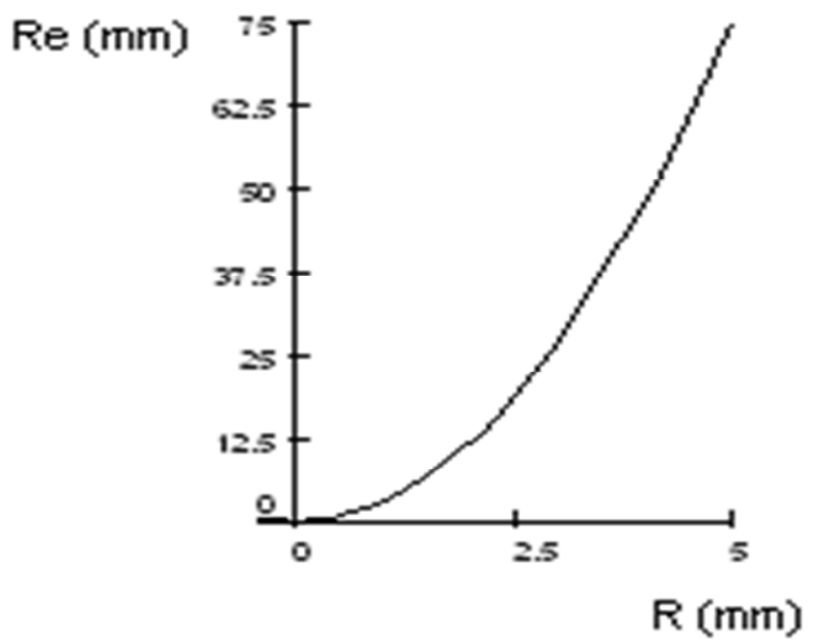

Figure 23. Curve to determine the radius of the semisphere from the radius of the lens $R e=$ Radius of the semisphere, $R=$ Radius of the spherical lens, $n=1.5$ is the index of refraction of the glass, $d=1 \mathrm{~mm}$ is the diameter of the optical fiber.

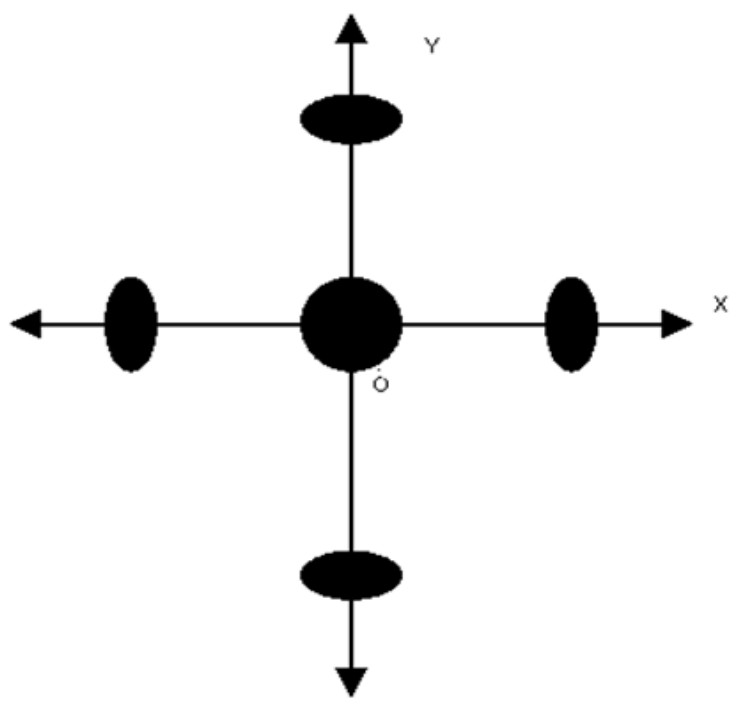

Figure 24. Pattern Image of five points analyzed in the simulation computational.

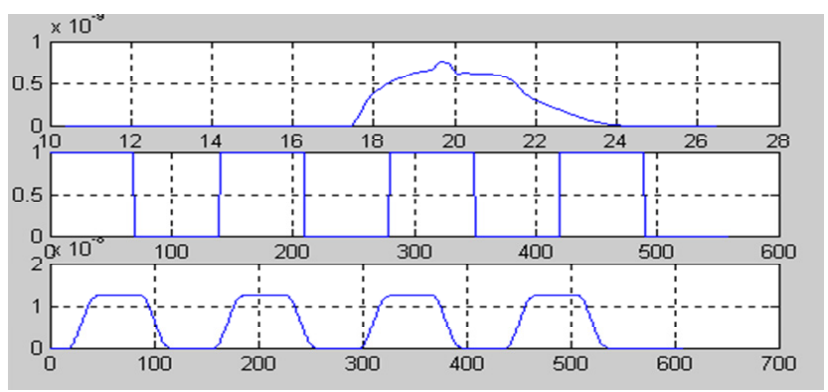

Figure 25. Result of the simulation computational. In the top part is observed the unitary impulse response, in the middle the transmitted pulses and in the low one the distortion of the pulses. 

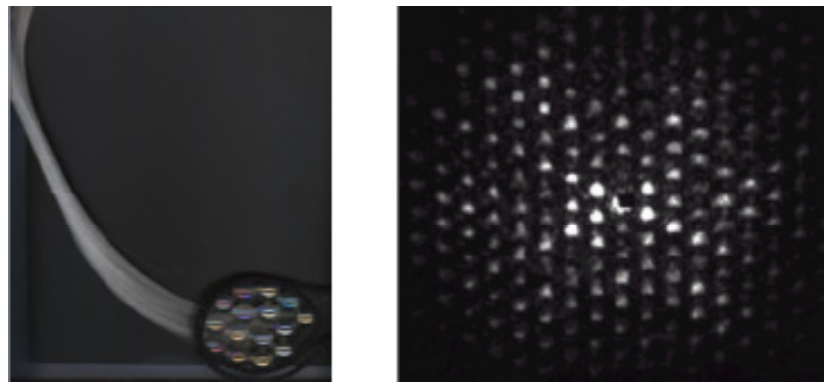

Figure 26. Array semispherical of photoemmitters/ photoreceivers simulating the eye of an insect.

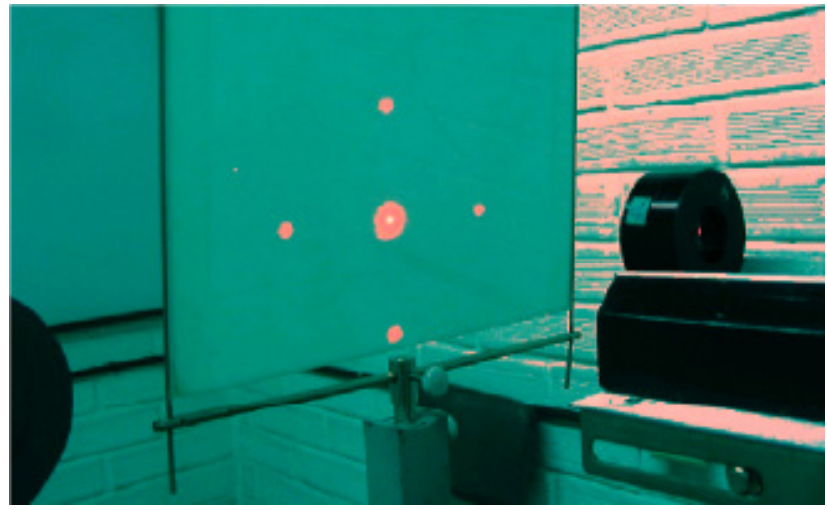

Figure 27. Optical images for incoherence spatially of a laser in a photoemmitter of Free Space (FSO).

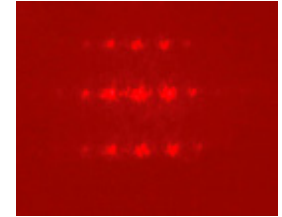

a

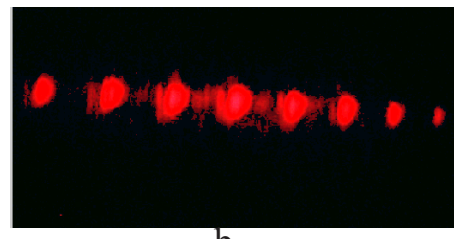

b
Figure 28. Optical images for incoherence spatially of a laser in photoemmitters of Free Space (FSO) in (a) spherical and (b)linear array.
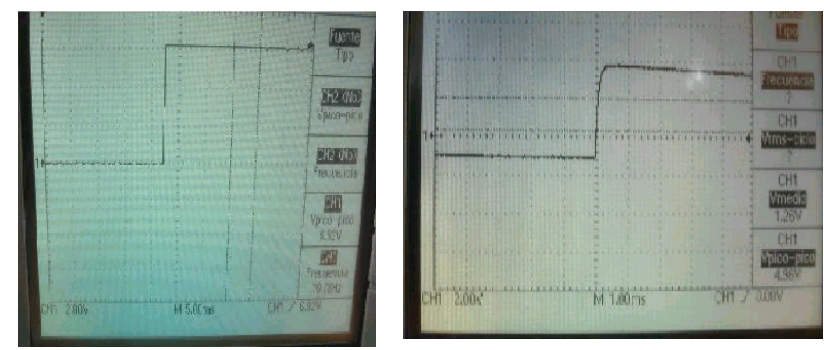

Figure 29. Transmitted pulse and received pulse.

Computational Simulation of an Infrared Communication System Indoor

To take totally advantage of the reflections of the infrared beams for the wireless communications indoor (figures 22 and 30), since every place, at which one is employed, changes his symmetry, it is necessary to take into account some aspects such as: the walls, roofs, or any other obstacle that presents this way to optimize the communications [9], [10, [11] and [12]. It has been designed a software that allows to calculate the variations of the environment in different configurations, where an equipment of communication is installed [13].

The temporary matrix and the coefficients distribution of impulse response is given for the equations (1) and (2), respectively

$$
\begin{aligned}
& t=t_{s i}+\sum_{k=1}^{n}\left(t_{i j}+t_{i j}^{\prime}\right)_{k}+t_{j r} \\
& h=h O_{s i} \prod_{k=1}^{n}\left(h_{i j}+h_{i j}^{\prime}\right)_{k} r O_{j r} \\
& {[t]=\left[t_{s i}\right]+(k-1) \cdot\left[t_{i j}\right]+\left(\left[t_{s i}\right]+(k-1) \cdot\left[t_{i j}\right]\right)} \\
& \left.[p]=\left[p_{s i}\right]\right]\left[p_{i j}\right]^{(k-1)}+\left(\left[p_{s i}\right] \cdot\left[p_{i j}\right](k-1)\right)^{\prime} \\
& t_{i j}=\left[\begin{array}{cccccc}
0 & t_{a b} & t_{a c} & t_{a d} & t_{a e} & t_{a f} \\
t_{b a} & 0 & t_{b c} & t_{b d} & t_{b e} & t_{b f} \\
t_{c a} & t_{c b} & 0 & t_{c d} & t_{c e} & t_{c f} \\
t_{d a} & t_{d b} & t_{d c} & 0 & t_{d e} & t_{d f} \\
t_{e a} & t_{e b} & t_{e c} & t_{e d} & 0 & t_{e f} \\
t_{f a} & t_{f b} & t_{f c} & t_{f d} & t_{f e} & 0
\end{array}\right] \\
& p_{i j}=\left[\begin{array}{cccccc}
0 & p_{a b} & p_{a c} & p_{a d} & p_{a e} & p_{a f} \\
p_{b a} & 0 & p_{b c} & p_{b d} & p_{b e} & p_{b f} \\
p_{c a} & p_{c b} & 0 & p_{c d} & p_{c e} & p_{c f} \\
p_{d a} & p_{d b} & p_{d c} & 0 & p_{d e} & p_{d f} \\
p_{e a} & p_{e b} & p_{e c} & p_{e d} & 0 & p_{e f} \\
p_{f a} & p_{f b} & p_{f c} & p_{f d} & p_{f e} & 0
\end{array}\right]
\end{aligned}
$$

and the symmetries in submatrix are:

$p b c=<p a c>, p b d=<p a d>, p b e=<p a e>, p b f=<p a f>, p$ $d e=\langle p c\rangle, p d f=\langle p c f\rangle$, where $\langle>$ signify that a rotation matrix around vertical center axis.

Of 36 sub-matrices that form to pij, only would be necessary to calculate 21 , but 6 of they are void (representing reflections of the walls on themsel- 
ves). The sub-matrix triangular inferior, with 15 sub-matrices, is calculated as of the sub-matrix triangular superior (with 15 sub-matrices) and that at the same time only requires to calculate 9 submatrices. Of 36 sub-matrices only are calculated 9, reducing thus considerably the calculation time and the necessary memory until the fourth part. Can be calculated by this method the impulse response coefficients, the times of the final radiation of the elements, before be directed toward the receiver, to put several receivers on different elements or positions, with its angles and its respective FOV and thus to facilitate the characterization of the IR channel. Permits to know the impulse response coefficients and times in an aperture of the room, as a door or window, facilitating thus the calculation of the evolution of the impulse response coefficients by multiple reflections in rooms with different forms and structures: H,L,F,E,T. The program can be used to calculate:

1. The evolution in the time of the radiation of each element of the walls of the room.

2. Total response to the unitary impulse in a specific receiver. If is intended to obtain the objective of the numeral 1 , only is needed to calculate:

a. The triangular matrix superior of tsi and of psi

b. The triangular matrix superior of tij and of pij

For to calculate total response to the unitary impulse (numeral 2) are required:

a. The row vectors $t s i$ and ho (times and coefficients between emitter and walls) with size $1 \times n t$ each one b. The row vectors tri and ro (times and coefficients between walls and receiver) with dimensions $1 \times n t$ each one

c. The triangular matrix superior of $t i j$ and of $p i j$ that, substituting in the equations, produce total response to the impulse in a receiver for each reflection:

$$
\begin{aligned}
& {[t]=\left(\sum_{i=1}^{n_{t}}\left(\left[t_{s i}\right]+\left((k-1)\left(\left[t_{i j}\right]+\left[t_{i j}\right]\right)+\left[t_{i r}\right]\right)\right)\right) / n_{t t}} \\
& {[p]=\left(\left(\left[h_{0}\right]\left[p_{i j}\right]^{(k-1)}+\left(\left[p_{i j}\right]\left[h_{0}\right]^{j}\right)\right) / n_{t t}\right) \cdot\left[r_{0}\right]}
\end{aligned}
$$

Using a program of channel simulation of the optical communications do not guided for infrared (figures 24 and 25), and with an experimental accomplishment in the laboratory (figures 26, 27, 28, 29 and 33), data has been took, doing spatially incoherent the beam of the laser and taking measures of distance from the laser to the obstacle, where the beam is reflected.

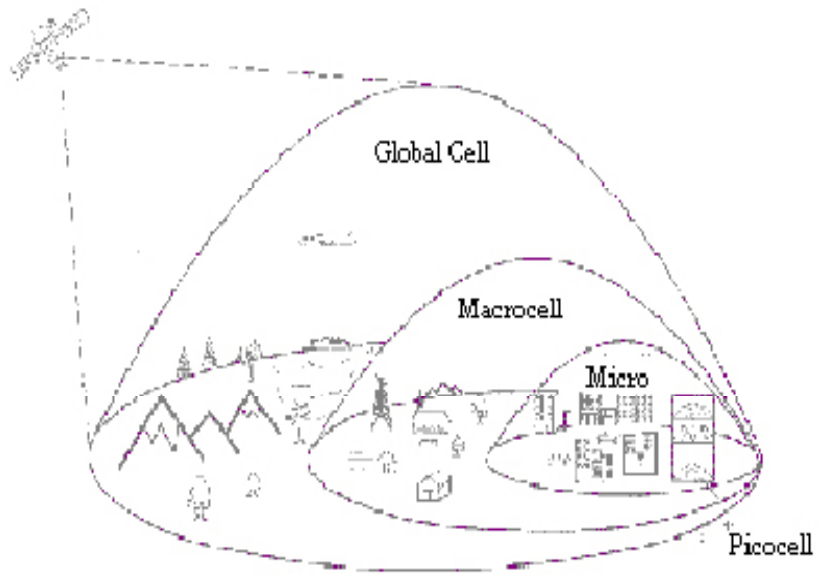

Figure 30. Propagation models in application of the spatial incoherence of the laser to the optical wireless communications indoor. Being located appropriately the array of points inside the room will be able to optimize the transmission velocity.

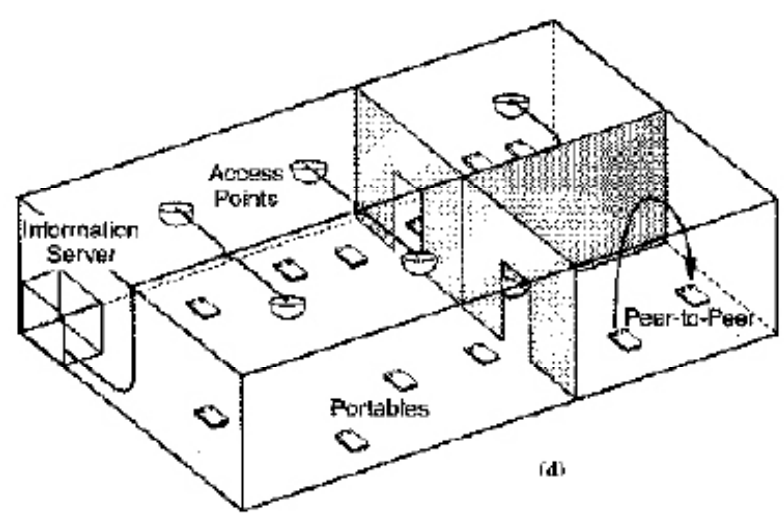

Figure 31. Connection of the Equipments.

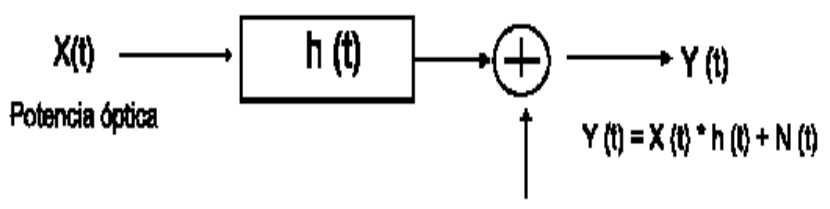

$N(t)$

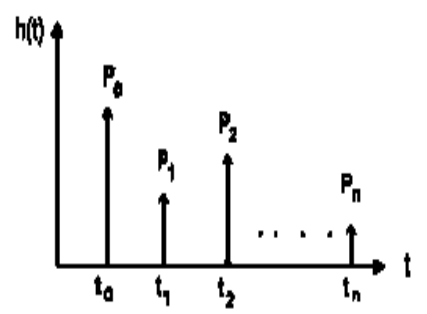

Figura 32. Impulsive Model. 


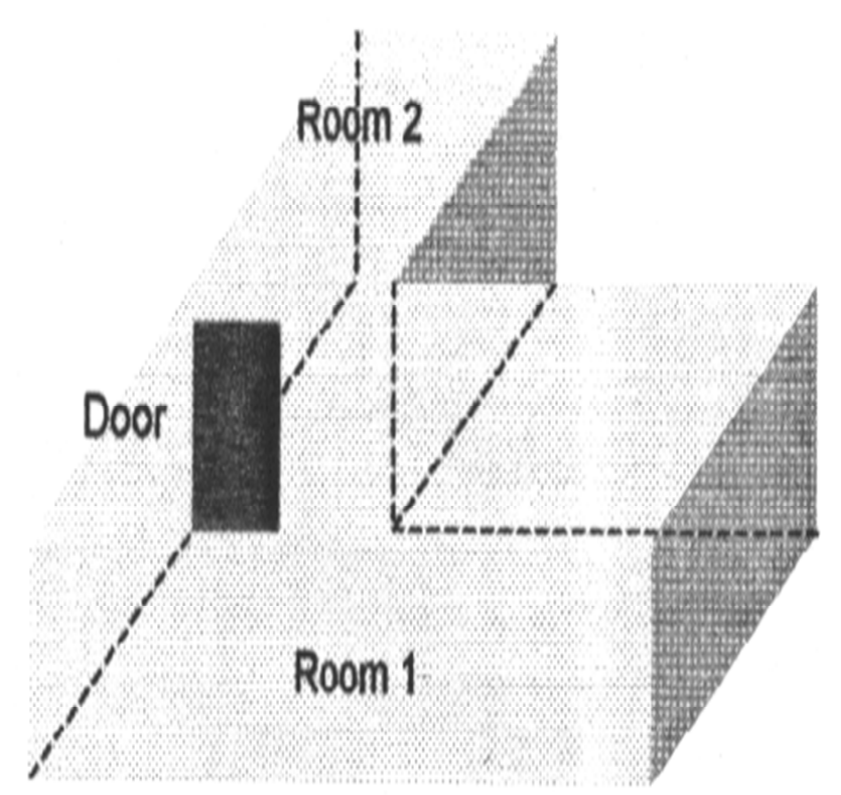

Figure 33. Asymmetric room example for calculation of the unitary impulse response.

The aperture (door) that communicates the vertical rooms 1 and the horizontal 2 is considered as an element $m_{l}$ (no reflecting) of wall of the room 1 and as the emitters of the room 2. Response to the impulse in the element $m_{l}, h_{l}(t)$, it is composed by an initial lighting $h o_{1}$ and by the contributions of the reflections of the other wall elements $h_{m l}(t)$.

$h_{1}(t)=h_{01} \delta(t)+h_{m 1}(t)$

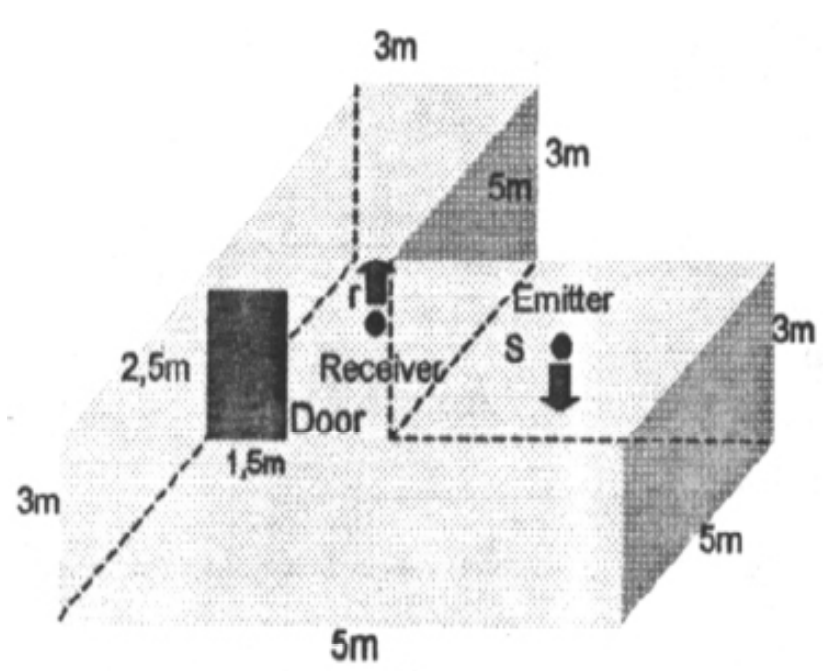

Figure 34. Description of size and positions of the door, transmitter and receiver in the asymmetric room

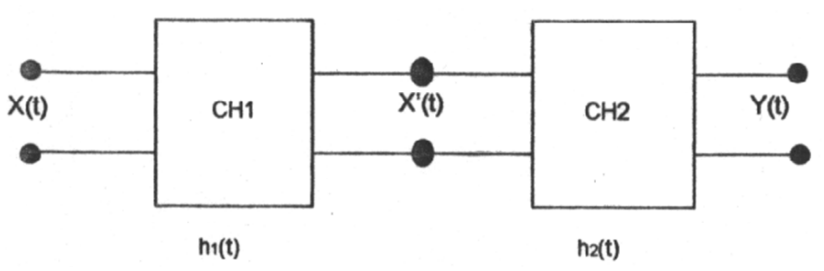

Figure 35. Block diagram for asymmetric room example.

The impulse response of the combined system (room 1 and room 2) in the form of $\Gamma$, is calculated with the equation

$$
h(t)=h_{1}(t) \otimes h_{2}(t)
$$

if the blocks $\mathrm{CH} 1$ and $\mathrm{CH} 2$ represent the corresponding channels to the rooms 1 and 2 respectively, and $X$ $(t)$ is the data signal transmitted from the room 1, then $Y(t)$ is the data signal in the receiver within the room 2 , that is calculated with the equation

$$
Y(t)=h(t) \otimes X(t)
$$

Therefore, can be found the temporary evolution of the impulse response coefficients in the door of entry from the room 1 to 2 , according as was indicated before. Also can be calculated the response to the impulse of the room 2 and the response to the impulse of the total system.
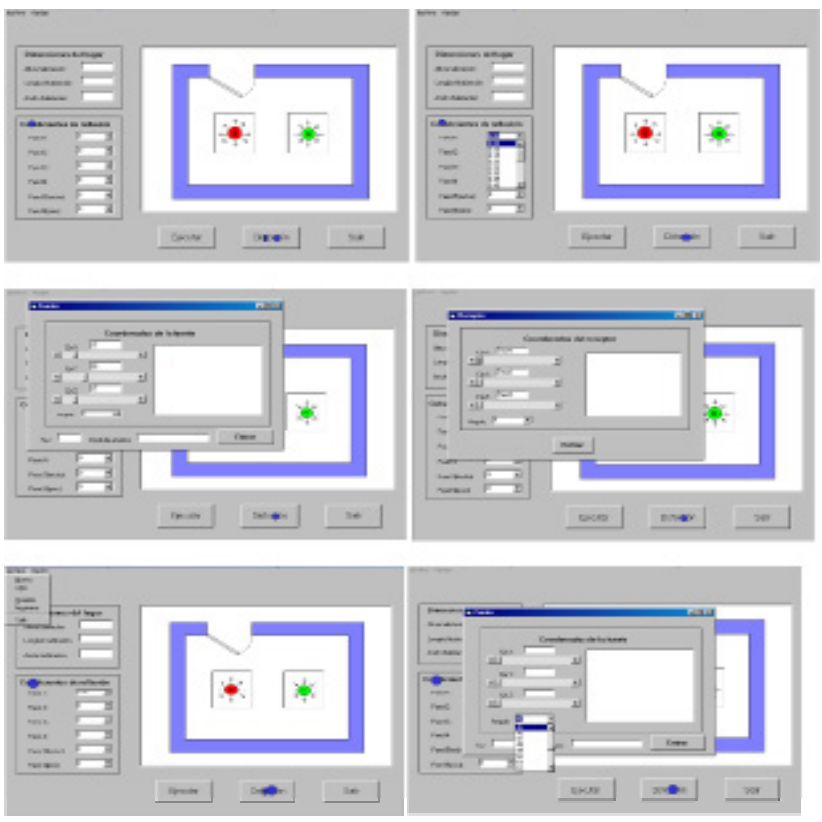

Figure 36. Windows for to insert the data in the software in the computational simulation of an infrared communication system indoor. 
Applications of the light laser with and bionic optimization to the optical wireless. Jaramillo y Achipiz.
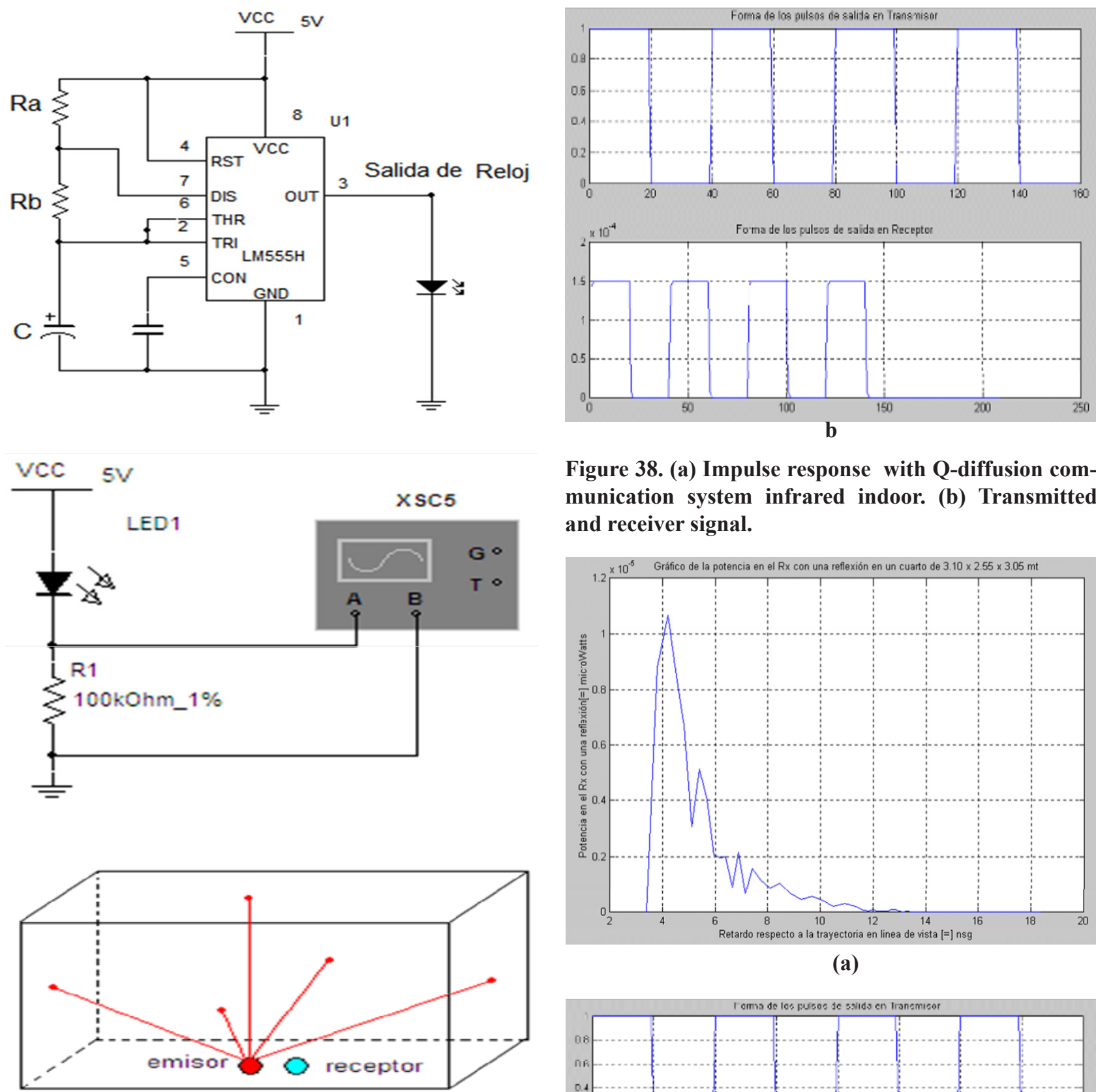

Figure 38. (a) Impulse response with Q-diffusion communication system infrared indoor. (b) Transmitted and receiver signal.

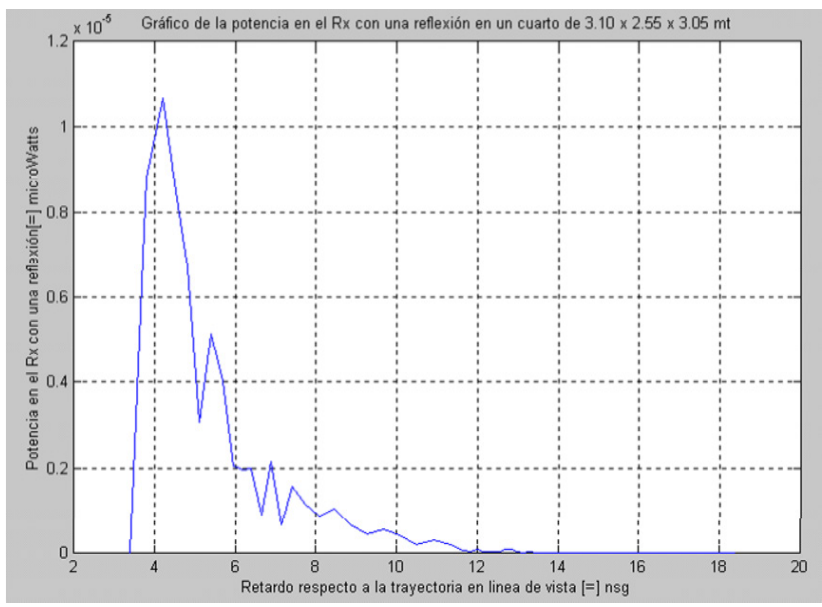

(a)
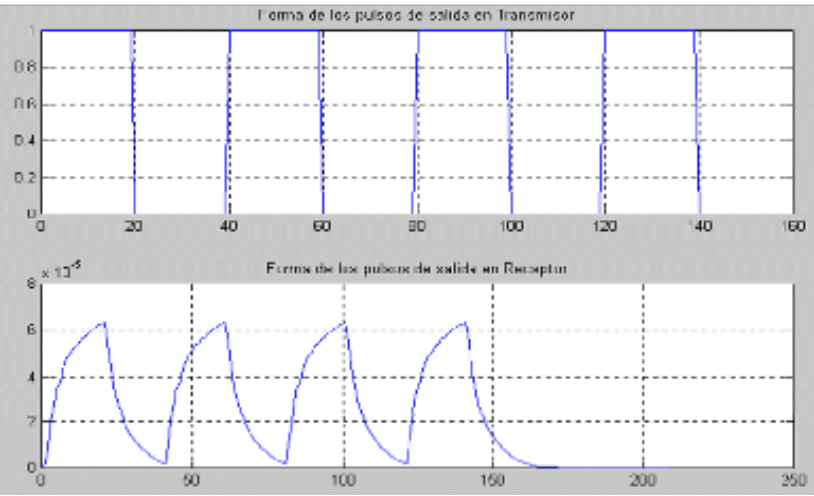

(b)

Figure 39. (a) Impulse response with diffusion communication system infrared indoor; (b) Transmitted and receiver signal. 


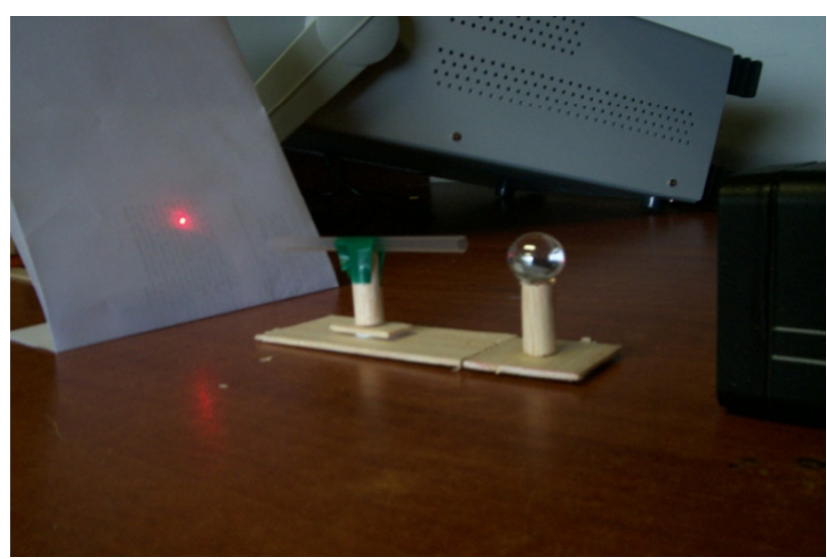

Figure 40. Appears the light wave transported by the optical fiber, with the distance adapted to the lens spherical. One can observes the signal in the screen.

\section{CONCLUSIONS}

FSO access networks are a complete flexible solution. However, actually there is few and imprecise information about capacities, technologies and architectures where Free Space Optics (or Free Space Optical) are applied. There is certain vacuum about information related to necessary networks elements for FSO designs, besides its characteristics. However, with not much information about FSO and using the standards of IrDA and ITU (about Optic Fibre PONs) and regarding basic knowledge about infrared technologies, designs and close estimations can be done in order to make initial decisions on business environments. Paths proposed to follow for investigating and studying are: FITL architectures with FSO, Infrared Access Multiplexing Systems, Design of Infrared Transmission Systems, developing of schemes and guides for designing FSO networks, $\mathrm{R}+\mathrm{D}$ on Broadband Infrared Emission and Reception Devices and Mathematical Modelling of such devices and FSO Systems.

One can make a mapping of the levels of power on a parallel plane to the floor of the room, being able to select the height and this way to know the different levels of power in the different points. One can also draw a grid diagram three-dimensional of the levels of power for different heights and different distributions of sources of radiation IR. The possible applications of the wireless communications for infrared are the Internet network of broadband up to speeds of $100 \mathrm{Mbps}$ to short distances and up to $10 \mathrm{Mbps}$ to distances of $100 \mathrm{~m}$ in networks LAN. For average distances can obtain speeds about the 30 to $50 \mathrm{Mbps}$. These results allow to transmit information, images and voi- ce simultaneously in a network Ethernet indoor, with utilization in industries with contaminated explosive environments, in museums to transmit information to every visitor, in rooms of conferences and concerts, and in applications of wireless Internet in the majority of the environments. Has been presented a method for the links not guided design using IR indoor with asymmetric ways rooms, in particular for rooms in a form of é, but that it can be generalized repeating the same procedure successively in the apertures or doors for other ways and structures of rooms, using one of efficient computational programs for the links design with IR indoor and with the feature from its high speed and that it can be used with a conventional PC. One has presented a method for doing incoherence spatially the light of the laser based on the concept of bionic and some results that will serve to optimize the bandwidth of the systems of optical communications.

This opens the way of researches and developments of new technological applications of low cost. It is necessary to use a laser of average power to observe the images to long distances and lenses combined with optical fibers to be able to have a major incoherence, since to major number of them, major quantity of points they can be seen in the space. From these results a program of simulation computational has been elaborated that allows comparing the theoretical values with the obtained ones experimentally, indicating that this is an original way for designing emitters and receivers of high performance for optical communications. The method that has been developed simplifies the calculations of the different parameters of the optical link, and allows finding of the bandwidth of the channel, facilitating the design of links FSO in the network of access across windows indoor. 


\section{REFERENCES}

1. L. Gasman and C.F. Gasman, "The Optical-Networking Business Environment", Communications Industry Researchers, (2001).

2. "Broadband Services", Nokia, Web ProForum Tutorials, www.iec.org, (2001).

3. D.M. Piscitello, "FSO: Extending Optical Networks where no Fiber has gone before", Core Competence, (2001).

4. M. Klimek, "Redes Ópticas Pasivas ATM", Alcatel: Revista de Telecomunicaciones, pp.258261, $4^{\circ}$ trimestre (2000).

5. E.D. Dennis, C.P. Wang, Y.C. Lin, Q.Zhan, "Should Ethernet or ATM be used as primary cable protocol for HFC", pp.6-9, (2001).

6. A. Dhir, "Home Networking Revolution: A Designer's Guide", Xilinx Inc., pp.47-62, (2001).

7. G. Agudelo Stephens and S. A. Jaramillo Flórez, The Last Mile Problem Solution using Free Space Optics Transmission Broadband, Proceedings International Telecommunication Symposium - ITS2002, Natal, Río Grande do Norte, RN, Brazil, Sept. (2002).

8. G.983.1, "Passive Optical Networks for Broadband Access", International Telecommunications Union, Nov. (1998).

9. S. A. Jaramillo Florez, "Contribución a la Gestión de Nuevos Servicios en una Red de Telecomunicaciones por Fibra Óptica en Colombia", PhD. Thesis Universidad Politécnica de Madrid, Spain, (1999).

10. K. Bogdánov, El Físico visita al Biólogo, Editorial MIR, Moscow, (1989).

11. S. A. Jaramillo Flórez, Imágenes Ópticas por Descoherencia Espacial de un Láser en un Optrón de Espacio Libre, Proceedings VIII Simposio de Tratamiento de Señales, Imágenes y Visión Artificial, Medellín, Colombia, Nov. (2003).

12. S. A. Jaramillo Flórez, Caracterización Sistémica de Optrones de Fibra Óptica y de Espacio Libre, Proceedings Primer Encuentro de Investigación, Innovación e Ingeniería en Telecomunicaciones y Áreas Afines, Centro de Investigación de las Telecomunicaciones - CINTEL Bogotá, Colombia Sept. (2003).

13. S. A. Jaramillo Flórez, Comunicaciones Ópticas por Infrarrojo, Proceedings $8^{\circ}$ Simposio Educación, Innovación y Desarrollo en Telecomunicaciones, Instituto Tecnológico Pascual Bravo, ITPB, 10 y 11 de octubre de 2002, Medellín, Colombia.

14. S. A. Jaramillo Flórez, Optimization of the Model for Optical Transmission Systems, Proceedings XIV Congresso Brasileiro de Automâtica - CBA2002, Natal, Río Grande do Norte, RN, Brazil, Sept. (2002). 